Int. Agrophys., 2021, 35, 25-30

\title{
Fruit removal forces of early stage pickling cucumbers for harvest automation**
}

\author{
Martina C. Jakob (1)* and Martin Geyer (D) \\ Horticultural Engineering, Leibniz Institute for Agricultural Engineering and Bioeconomy, \\ Max-Eyth-Allee 100, 14469, Potsdam, Germany
}

Received November 6, 2020; accepted December 21, 2020

\begin{abstract}
European growers are demanding selective mechanical harvesting solutions, such as robotic solutions, because hand harvesting is extremely labour intensive. Mechanical harvesting depends on low fruit retention forces between fruit and plant. Over two consecutive growing seasons, including a winter greenhouse trial, more than 1600 samples were taken to determine the fruit removal force of early stage cucumbers for pickling and canning. Compared to studies with other fruit the fruit removal force of cucumbers was fairly high and also showed a large degree of variation. A significant percentage of the harvest had stalk residues, which cause the expenditure of extra man-hours on the processing lines. It was therefore concluded, that mere pulling is not sufficient to disconnect the fruit. Harvesting robots require an extra device for ease of separation.
\end{abstract}

Keywords: Gherkin, fruit removal force, bonding force, automated harvest

\section{INTRODUCTION}

In botanical terms, the fruit of the cucumber (Cucumis sativus L.) is a pepo, a berry with a very tough exocarp. It may be classified as a non-climacteric fruit and originates from Asia and Africa, where it has been used as a food source for more than 3000 years. Cucumbers are one of the most popular vegetables in the world, they are a particularly popular choice for pickling (Staub et al., 2008). According to the FAO (2020) statistics, the world production was 75 million tons in 2018. There are different varieties for slicing or pickling, and within these varieties several cultivars (mainly hybrids) have been created. There are three

*Corresponding author e-mail: mjakob@atb-potsdam.de

**This work was associated with the Echord++ EU project CATCH - Cucumber Gathering - Green Field Experiments (2017). distinct uses for cucumbers in the marketplace: fresh whole, fresh sliced, and pickled (Tatlioglu, 1993). Cucumbers are grown in either fields or green houses and there are several training systems used for production (Tatlioglu, 1993). There are two methods of harvesting cucumbers, handpicking and machine harvest. In the United States and also in Asia the mechanical one-time harvest is common for outdoor cucumber production, but the quality and size of the products after harvest show a large variation. Cucumbers are creeping plants and continuously produce flowers and fruit when pollinated. They are best picked before their seeds become hard and are eaten in an immature state. A cucumber is considered to be of high quality, when it is uniformly green, firm and crisp. If a fruit is left on the plant, the skin becomes tough and turns yellow. In order to maintain plant productivity it is necessary to regularly harvest the fruit. To date, continuous harvest could only be accomplished through handpicking. During a one-time harvest, the whole plants are cut, transported on a sieving belt and pulled through two tight, rotating rollers. The cucumbers are disconnected mechanically by a pinch roller mechanism (Rotz et al., 1982). However, this method is only suitable for large cucumbers. Small cucumbers are either damaged or lost (Surdilovic and Geyer, 2013). One-time harvesting stops the production process, while handpicking can maintain cultivation over several months. One-time harvesting is not suitable for pickling cucumbers, where the largest profit margin is achieved for sizes between 6 and $9 \mathrm{~cm}$.

(C) 2021 Institute of Agrophysics, Polish Academy of Sciences 
Handpicking is very labour intensive, and rising wages increase production costs. European growers are demanding selective mechanical harvesting solutions, such as robotic solutions, but the use of field robots is challenging regarding their functionality and especially their longevity in harsh outdoor environments (Villa-Henriksen et al., 2020). Dust, humidity or vibration due to uneven surfaces affect their functionality, life-span and increase maintenance. Handpicking small pickling cucumbers includes several processes such as fruit detection, selection and separation. This particular study focuses on the separation of cucumbers. During hand harvesting, this is actively achieved by grabbing the fruit, bending and pressing the stalk to the side and finally disconnecting the fruit by pulling gently or pushing the stalk so it comes off. These requirements complicate the harvesting process, but they seem to be necessary to harvest fruit without a stalk. For the efficient processing of the cucumbers, it is not acceptable that too many stalks or parts of the stalk remain on the fruit. Removing the remaining stalks for canning purposes leads to the expenditure of extra effort in the processing lines, therefore processing plants require fruit without a stalk. On the other hand, the separation of fruit without specific and complex techniques requires a low bonding force between the fruit and plant. Currently, detailed and exact information concerning the force required to remove the pickling cucumbers from the plant through the use of a pulling motion alone is completely lacking. Similarly, it is still not known whether the fruit removal force (FRF) of cucumbers is cultivar-dependent or whether FRF changes during the developmental stages particularly relevant for pickling cucumbers.

The fruit removal force describes the nature of the bond between the fruit and plant and is an important characteristic for evaluating the suitability of a cultivar for mechanical harvesting, since the efficiency of harvesting devices is directly related to a lower detachment force (Bukovac, 1979). The FRF is also used as an indicator to measure the activity of chemicals (i.e. etephon) which is used to loosen the bond between fruit and plant. In general, the FRF increases in early fruit development and decreases during ripening (Wittenbach and Bukovac, 1974). Some cultivars develop a fruit abscission zone upon ripening. Coffee beans for example, have a lower FRF when they are ripe, but various cultivars differ to a considerable extent (Crisosto and Nagao, 1991). For olives, a correlation was found between fruit size and the FRF (Lavee et al., 1982; Almeida et al., 2015). A recent Australian study concerning olive cultivars found that FRF decreased from the first harvest to the fifth harvest (Alowaiesh et al., 2016). Castillo-Ruiz et al. (2018) found that FRF decreased when it was measured after applying stalk-twisting angles. For sour cherries, the FRF describes the ripening process. Nevertheless, pickling cucumbers have not been investigated to date, and based on the fact that the FRF is higher in early fruit development, we were expecting strong bonding forces. The study was part of an EU Cornet project 'CATCH' (Fraunhofer, 2018), to investigate the detection and selective robotic harvesting of pickling cucumbers. The knowledge obtained will facilitate the further development of autonomous harvesting robots.

The aim of this study was to determine the FRF of early stage cucumbers for pickling and canning in order to investigate their suitability for robotic harvesting.

\section{MATERIAL AND METHODS}

The field trials took place in the "ATB Fieldlab for Digital Agriculture' in Marquardt, Germany, during the summer periods in 2017 and 2018. The annual precipitation for this area was $581 \mathrm{~mm}$ in 2017 and $319 \mathrm{~mm}$ in 2018 . The normal average yearly precipitation for this area which was measured between 1981 and 2010 was $589 \mathrm{~mm}$. As an additional source of water, drip irrigation with fertilization was installed. In order to reduce evaporation and weeds, mulching foils were used to cover the rows.

Seeds were sown directly into the field in mid-May in order to avoid low temperatures both during and after germination. The distances between the rows were $150 \mathrm{~cm}$ and the plants were $30 \mathrm{~cm}$ apart, following the common recommendation for multiple hand harvesting systems. In comparison to a plant arrangement designed to suit a single machine harvest, these distances are large.

Eight different cultivars from Rijk Zwaan, (Velver, Germany) were selected from a pickling variety. The following five cultivars were grown in 2017 in the field and in a greenhouse: 'Liszt', 'Strawinsky', 'Quirk', 'Karaoke' and 'Componist'. In 2018 'Liszt' was cultivated again, but the other cultivars were replaced by 'Majestosa', 'Kybria' and 'Trilogy'. The cultivar 'Quirk' represented a new cultivar that was specifically bred to achieve a lower bonding force between the fruit and plant. 'Liszt' and also 'Strawinsky' are extremely open, non-branched variants. 'Karaoke' has dark green and blueish leaves and 'Componist' is a yellowgreen-type with yellowish leaves. In order to study a wider range of varieties, three varieties were replaced by others in 2018. In autumn 2017, the same five cultivars used in the field trial were grown in a greenhouse in Grossbeeren, Germany, with drip irrigation, following the 2017 outdoor season. The row distances were also $150 \mathrm{~cm}$ and the plants were grown $30 \mathrm{~cm}$ apart.

In order to measure the force required to remove a cucumber from the plant, an FK 100 digital force gauge (Sauter GmbH, Balingen, Germany) was used. Peak hold forces $(\mathrm{N})$ were determined by placing randomly selected cucumbers of adequate size in an especially crafted holder and then pulling upwards until the fruit was detached (Fig. 1).

Over a period of six weeks from August 2017 until the end of September 2017, the fruit was harvested on six occasions. Each time the peak force was recorded for the 


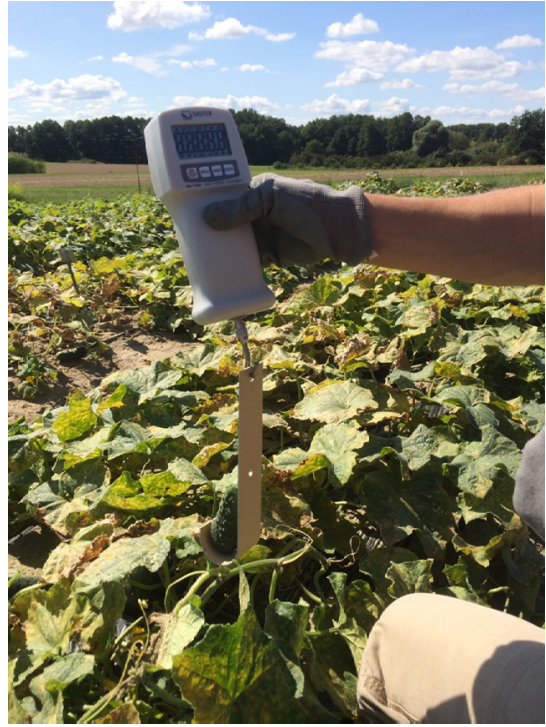

Fig. 1. Sauter FK 100 force gauge and fruit holder.

Table 1. Cultivation scheme

\begin{tabular}{|c|c|c|c|}
\hline \multirow{2}{*}{ Experiment } & \multicolumn{2}{|c|}{2017} & \multirow{2}{*}{$\begin{array}{r}2018 \\
\text { Field }\end{array}$} \\
\hline & Field & Greenhouse & \\
\hline \multirow[t]{5}{*}{ Variety } & Liszt & Liszt & Liszt \\
\hline & Karaoke & Karaoke & Majestosa \\
\hline & Strawinsky & Strawinsky & Kybria \\
\hline & Componist & Componist & Triology \\
\hline & Quirk & Quirk & - \\
\hline Area $\left(\mathrm{m}^{2}\right)$ & 360 & 200 & 360 \\
\hline \multicolumn{4}{|c|}{ Spacing (row $\times$ plant) $1.5 \times 0.3 \mathrm{~m}$} \\
\hline Sample size & 495 & 862 & 318 \\
\hline
\end{tabular}

Table 2. Fruit removal forces $(N)$ in the different trials and sample size ' $n$ '

\begin{tabular}{|c|c|c|c|c|c|c|c|c|}
\hline \multirow{2}{*}{ Data } & \multicolumn{8}{|c|}{ Variety } \\
\hline & Liszt & Majestosa & Karaoke & Quirk & Strawinsky & Kybria & Trilogy & Componis \\
\hline \multicolumn{9}{|c|}{ Field 2017} \\
\hline $\begin{array}{l}\operatorname{Avg} \pm \\
(\min , \max )\end{array}$ & $\begin{array}{l}10.5 \pm 4.8 \\
(2.3,28.8)\end{array}$ & & $\begin{array}{l}12.9 \pm 6.1 \\
(1,35)\end{array}$ & $\begin{array}{l}9.7 \pm 4.3 \\
(2.5,23.2)\end{array}$ & $\begin{array}{l}13.4 \pm 6.1 \\
(2.3,34.3)\end{array}$ & & & $\begin{array}{l}12.9 \pm 5.8 \\
(2.3,23.5)\end{array}$ \\
\hline $\mathrm{n}$ & 50 & & 177 & 100 & 128 & & & 40 \\
\hline \multicolumn{9}{|c|}{ Greenhouse 2017} \\
\hline $\begin{array}{l}\operatorname{Avg} \pm \\
\text { (min, max) }\end{array}$ & $\begin{array}{l}10.9 \pm 4.7 \\
(2.8,30.2)\end{array}$ & & $\begin{array}{l}15,6 \pm 6.3 \\
(3.5,36)\end{array}$ & $\begin{array}{l}10.2 \pm 4.1 \\
(1.5,21.7)\end{array}$ & $\begin{array}{l}13.4 \pm 5.2 \\
(3.5,29.2)\end{array}$ & & & $\begin{array}{l}11.4 \pm 5.1 \\
(2.9,27.1)\end{array}$ \\
\hline \multicolumn{9}{|c|}{ Field 2018} \\
\hline $\begin{array}{l}\operatorname{Avg} \pm \\
(\min , \max ) \\
\mathrm{n}\end{array}$ & $\begin{array}{l}19.1 \pm 8.2 \\
(5.3,56.5) \\
79\end{array}$ & $\begin{array}{l}20.3 \pm 8.3 \\
(3.4,42.8) \\
79\end{array}$ & & & & $\begin{array}{l}19.3 \pm 8.9 \\
(5,45.9) \\
80\end{array}$ & $\begin{array}{l}17.2 \pm 7.9 \\
(3.7,40.8) \\
80\end{array}$ & \\
\hline
\end{tabular}

randomly selected cucumbers and also the exact length and mass of each fruit were determined later on in the laboratory. During autumn, greenhouse plants of the same cultivars were analysed accordingly.

A statistical analysis was carried using JMP 14 (Marlow, Buckinghamshire, United Kingdom). A student t-test was used to evaluate the differences between two samples as the results followed a normal distribution. A regression analysis was used to reveal any correlations.

\section{RESULTS}

In 2017, a total of 495 cucumbers of all cultivars were harvested on six different days. This process was repeated in 2018 on 11 separate days for 318 fruit, with each cultivar representing the same share. The greenhouse experiments of 2017 included 862 fruit sampled on six days between the end of October and the middle of December. The cultivar sample sizes (n) are displayed in Table 1.

The measured FRF over all cultivars varied widely within the period of one day and also over the harvesting period in all trials. In 2018, the average forces required to harvest the different cultivars were higher than in 2017 (Table 2), but only the cultivar 'Liszt' was measured in both years. The average FRF for 'Liszt' increased significantly from $10.5 \mathrm{~N}$ in 2017 to $19.1 \mathrm{~N}$ in 2018 .

The median fruit removal forces for all cultivars ranged between 9.7 and $20.3 \mathrm{~N}$. The full range of forces measured varied from $1.5 \mathrm{~N}$ to $56.5 \mathrm{~N}$. A large difference between the two trials in summer 2017 and 2018 in the average FRF was found; an average force of $19 \mathrm{~N}$ was measured for four cultivars in 2018, while it was $11.9 \mathrm{~N}$ for all five cultivars in 2017 and 12.4 if 'Quirk' is left out.

The FRF of the cultivar 'Quirk' differed significantly to 'Karaoke', 'Strawinsky' and 'Componist' in the 2017 field trials $(p \leq 0.002)$. The fruit of the cultivar 'Liszt' 


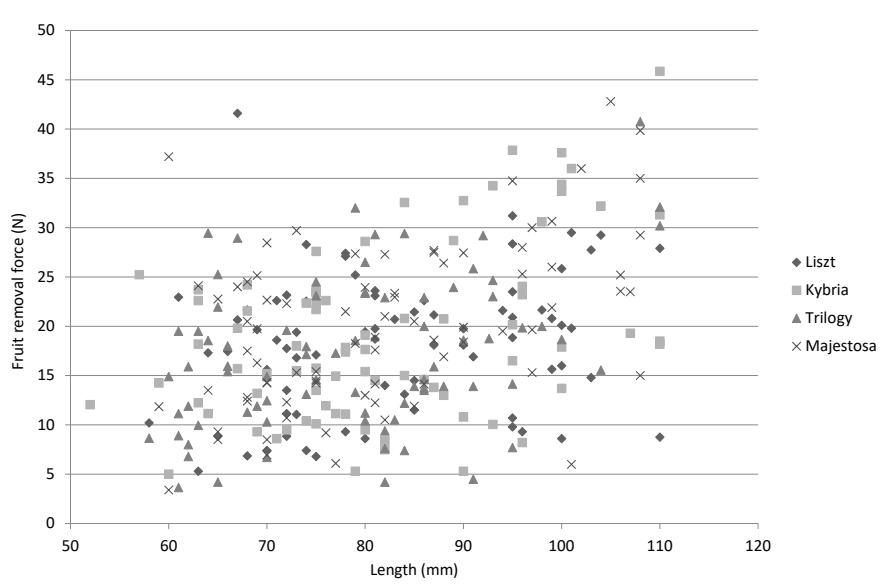

Fig. 2. Fruit removal forces of 'List', 'Kybria', 'Trilogy' and 'Majestosa' in relation to fruit length.

also required significantly lower forces in comparison to 'Karaoke' and 'Strawinsky' $(\mathrm{p} \leq 0.008)$. During the greenhouse trial 'Karaoke' and 'Strawinsky' required significantly higher FRF values in comparison to the other cultivars. 'Trilogy' required significantly lower forces than 'Majestosa' $(p=0.02)$ while there was no difference between the other cultivars. However, there was no dependency between the force and length or mass of the fruit in any of the trials, but length and mass are linearly correlated. The relationship between mass, diameter and FRF was tested for the sample in 2018, but $\mathrm{r}^{2}$ was found to be 0.1 and lower for all of the samples (Fig. 2).

Pickling cucumbers for canning must be harvested without the stalk. Therefore, hand pickers bend the cucumbers and press the stalk to one side with their thumbs so as to detach the fruit minus the stalk. When the fruit were harvested with the force gauge alone, there were differences between the cultivars depending on whether the stalk and cucumber were disconnected.

Table 3 shows the distribution of fruit with and without the stalk in different trials and for all cultivars. It also shows that the percentage of fruit with a residue of stalk was always higher than those without a stalk except for one sample, when the fruit is merely pulled off the plant without bending or twisting. The variety 'Liszt' formed a part of all of the experiments. In 2017, the percentage of fruit without a stem for 'Liszt' was very low, but in 2018, 59\% of the fruit had no stalk remaining after they were pulled off. An equally successful result of separating the fruit and stalk was only achieved by 'Quirk' in the greenhouse trial of 2017.

\section{DISCUSSION}

In comparison with apricots that required values of $5 \mathrm{~N}$ (Erdogan et al., 2003) or olives with 2 to $8 \mathrm{~N}$ (Lavae et al., 1982; Khdair et al., 2018), the average fruit removal force required to remove the analysed cucumbers was relatively high, but low in comparison with oranges which produced results of 69 to $115 \mathrm{~N}$ (Sanders, 2005). The range of FRF determined for cucumbers was generally larger than that of olives and apricots. Almeida et al., 2015 determined the FRF relationship to fruit mass to increase harvesting efficiency, but in general with increasing fruit size the FRF increases (Lavee et al., 1982; Castillo-Ruiz et al., 2018). In the 2018 field trial, the average ratio of FRF to mass was determined to be 73 for cucumbers, the values ranged from 13 to 364 . Due to this large degree of variation, it seems that the $\mathrm{FRF} /$ mass ratio is not a relevant parameter with which to determine the optimal harvesting date or characterize the harvesting efficiency of immature cucumbers. This is also supported by the fact that there was no correlation found between fruit length and FRF (Fig. 2).

Table 3. Characteristics of disconnection by pulling (with stalk/without stalk, \%)

\begin{tabular}{lcccccccc}
\hline & \multicolumn{7}{c}{ Variety with stalk/without stalk (\%) } \\
\cline { 2 - 8 } Experiment & Liszt & Majestosa & Karaoke & Quirk & Strawinsky & Kybria & Trilogy & Componist \\
\hline Field 2017 & $88 / 12$ & - & $85 / 15$ & $74 / 26$ & $84 / 16$ & - & - & $80 / 20$ \\
Greenhouse 2017 & $81 / 18$ & - & $75 / 25$ & $51 / 49$ & $84 / 17$ & - & - & $77 / 23$ \\
Field 2018 & $41 / 59$ & $70 / 30$ & - & - & - & $71 / 21$ & $81 / 19$ & - \\
\hline
\end{tabular}


It was not determined whether FRF decreased with the increasing maturity of the cucumbers, because cucumbers do not meet the required quality standards when they increase in size. Wittenbach and Bukovac (1974) found that FRF increases in early fruit development and decreases during ripening. Therefore, one could expect that this is also the case for cucumbers and the high forces required for harvesting may be explained by the early developmental stage during which time the cucumbers were harvested.

The fairly low FRF of the 'Quirk' cultivar may be explained by selective breeding which aimed to achieve this particular property. The difference in the overall averages between the summer trials of 2017 and 2018 cannot be explained by the variables measured. In 2018, precipitation was significantly lower, but the plants were irrigated. Nevertheless, a lower precipitation value may result in more sunshine and higher temperatures, thus the effect could be induced by heat stress. If higher plant species are exposed to excess heat, at least $5^{\circ} \mathrm{C}$ above their optimal growing conditions exhibit a characteristic set of cellular and metabolic responses required for the plants to survive the relatively high temperature conditions (Guy, 1999). If the bonding force between the fruit and plant is influenced by heat stress this should be investigated further. Moreover, if it turns out that the bonding force increases under heat stress, this factor must be taken into account in any case from the point of view of climate change. Further measurements should also incorporate the thickness, flexibility and length of the stalk.

The fruit removal force (FRF) is an important characteristic for evaluating the suitability of a cultivar for mechanical harvesting, this is the case because the efficiency of harvesting devices is directly related to low detachment forces (Bukovac, 1979). Both a high FRF value as well as stalk residues seem to complicate the automated harvesting of pickling cucumbers. Chemicals (i.e. etephon) may be used to reduce the FRF, but this technique is not used in practice for either hand picking nor in the one-time machine harvest of cucumbers. Therefore, an automated solution is required to actively disconnect the fruit from the plant at the base of the stalk. Nevertheless, the significantly lower FRF of the relatively new cultivar 'Quirk' has shown that breeding programs could simplify automated solutions.

This study was associated with an EU project which aimed to develop an autonomous harvesting platform for cucumbers, consisting of two robot arms grabbing and disconnecting the fruit using only a pulling motion. While greenhouse robotic harvesting solutions for cucumbers use a thermal knife to remove the fruit (van Henten et al., 2002), field robots should ideally be kept as simple as possible. Outdoor machines have to contend with the natural environment which poses significant challenges to both their functionality and longevity (Villa-Henriksen et al., 2020). The disconnection of tree fruit like olives for oil or apples for juice production is commonly accomplished by shaking the tree. In this case, the force required to disconnect the fruit is influenced by the torsional forces applied to the stem. However, shaking cucumber plants is not a viable option.

Torsional forces were not investigated in this study, but Castillo-Ruiz (2018) found that twisting and bending increased the harvesting efficiency for olives, thereby achieving accelerated detachment. Therefore, the question remains as to whether or not it is sufficient to apply torsional forces to the cucumber fruit to disconnect it rather than using a cutting device.

\section{CONCLUSIONS}

1. The fruit removal force of different cucumber cultivars showed a large range and variation between years and cultivars.

2. No correlation was found between fruit removal force and mass or length within the samples.

3 . The observed average forces were too high to disconnect the fruit by just pulling it without restraining the plant and the amount of stalk residues was also too high for direct processing.

4. As growers are seeking an automated solution for harvesting, the results indicate that the separation process requires a combination of gripping and active disconnection using a tool to remove the fruit without damaging the plant or the fruit and avoiding residual stalks.

\section{ACKNOWLEDGEMENT}

We would like to thank Dr. Werner Herppich for his proofreading and the support to improve the manuscript.

\section{REFERENCES}

Almeidaa A., Figueiredoa T., and Fernandes-Silva A., 2015. Data used as an indicator of mechanical olive harvest season. Agric. Agricult. Sci. Proc., 7, 2-5.

Alowaiesh B., Singh Z., and Kailis S.G., 2016. Harvesting time influences fruit removal force, moisture, oil content, free fatty acids and peroxide in the oil of Frantoio and Manzanilla olive cultivars. Am. J. Chemical Sci., 10(12), 1662-1668.

Bukovac M.J., 1979. Machine-harvest of sweet cherries: Effect of etephon on fruit removal and quality of processed fruit. J. Am. Society Hort. Sci., 104, 289-294.

Castillo-Ruiz F.J., Tombesi S., and Farinelli D., 2018. Olive fruit detachment force against pulling and torsional stress. Spanish J. Agric. Res., 16(1). https://doi.org/10.5424/ sjar/2018161-12269

Craker L.E. and Abeles F.B., 1969. Abscission: quantitative measurement with a recording abscissor. Plant Physiol., 44, 1139-1143.

Crisosto C.H. and Nagao M A., 1991. Evaluation of fruit removal force of coffee cultivars. Horti. Sci., 26(2), 210.

Erdogan D., Guner M., Dursun E., and Gezer I., 2003. Mechanical harvesting of apricots. Biosystems Eng., 85(1), 19-28. 
Estornell L.H., Agusti J., Merelo P., Talon M., and Tadeo F.R., 2013. Elucidating mechanisms underlying organ abscission. Plant Sci., 199-200, 48-60. https://doi.org/10.1016/j. plantsci.2012.10.008.

FAO, 2020. Statistics 2018. http://www.fao.org/faostat/en/\#data/ QC/visualize (accessed on 15 May 2020).

Ferguson L., Rosa U.A., Castro-Garcia S., Lee S.M., Guinard J.X., Burns J., Krueger W.H., O'Connell N.V., and Glozer K., 2010. Mechanical harvesting of California table and oil olives. Advances Hort. Sci., 24(1), 53-63.

Fraunhofer, 2018. Lightweight robots harvest cucumbers. https:// www.fraunhofer.de/content/dam/zv/en/press-media/2018/ February/ResearchNews/lightweight-robots-harvestcucumbers.pdf (accessed on 11 May 2020).

Guy C., 1999. Molecular responses of plants to cold shock and cold acclimation. J. Mol. Microbiol. Biotechnol., 1, 231-242.

Hua Y., Zhang N., Yuan X., Quan L., Yang J., Nagasaka K., and Zhou X.-G., 2019. Recent advances in intelligent automated fruit harvesting robots. Open Agric. J., 13, 101-106.

Khdair A.I., Abu-Rumman G., and Khdair S., 2018. Evaluation the mechanical harvesting efficiency of olive with the application of fruit loosening spray. CIGR J., 20(4), 69-75.

Lavee S., Avidan B., and Ben-Tal Y., 1982. Effect of fruit size and yield on the fruit-removal force within and between olive cultivars. Scientia Horticulturae, 17, 27-32.

Motsenbocker C.E., 1996. Detachment force and fruit characteristics of tabasco pepper at several stages of development. Hort. Sci., 31(7), 1231-1233.

Roberts J.A., Elliott K.A., and Gonzalez-Carranza Z.H., 2002. Abscission, dehiscence, and other cell separation processes. Annual Review Plant Biol., 53, 131-158. https://doi. org/10.1146/annurev.arplant.53.092701.180236.

Rotz C.A., Herrington D.A., Brown G.K., Ledebuhr R.L., and Marshall D.E., 1982. Mechanical Harvesting of Small Pickling Cucumbers. Trans. ASAE, 25(1), 13-17.

Sanders K.F., 2005. Orange harvesting systems - Review. Biosystems Eng., 90(2), 115-125. https://doi.org/10.1016/j. biosystemseng.2004.10.006.
Shamshiri R., Weltzien C., Hameed I., Yule I., Grift T., Balasundram S., Pitonakova L., Ahmad D., and Chowdhary G., 2018. Research and development in agricultural robotics: A perspective of digital farming. Int. J. Agric. Biol. Eng., 4, 1-14. https://www.ijabe.org/index.php/ ijabe/article/view/4278/1737.

Statistisches Bundesamt (Destatis), 2020. Gemüseerhebung Anbau und Ernte von Gemüse und Erdbeeren 2019. https:// www.destatis.de/DE/Themen/Branchen-Unternehmen/ Landwirtschaft-Forstwirtschaft-Fischerei/Obst-GemueseGartenbau/_inhalt.html.

Staub J.E., Robbins M.D., and Wehner T.C., 2008. Cucumber. In: Handbook of Plant Breeding. Vegetables I. (Eds J. Prohens, F. Nuez). Springer, New York, NY. https://doi. org/10.1007/978-0-387-30443-4_8

Surdilovic J. and Geyer M., 2013. Mechanical harvest of pickling cucumbers. Landtechnik, 68(3), 183-256. https://doi. org/10.15150/1t.2013.225.

Tatlioglu T., 1993. 13-Cucumber: Cucumis sativus L. In: Genetic Improvement of Vegetable Crops (Eds G. Kalloo, B.O. Bergh). Pergamon, 197-234.

Tucker M.L. and Kim J., 2015. Abscission research: what we know and what we still need to study. Stewart Postharvest Review, 11(2), 1-7. doi:10.2212/spr.2015.2.1.

Van Henten E.J., Hemming J., Van Tuijl B.A.J., Kornet J.G., Meuleman J., Bontsema J., and Van Os E.A., 2002. An autonomous robot for harvesting cucumbers in greenhouses. Autonomous Robots, 13(3), 241-258.

Villa-Henriksen A., Edwards G.T.C., Pesonen L.A., Green O., and Sörensen C.A.G., 2020. Internet of Things in arable farming: Implementation, applications, challenges and potential. Biosys. Eng., 191, 60-84. https://doi.org/10.1016/j.biosystemseng.2019.12.013.

Vinokur Y., Rodov V., Levi A., Kaplunov T., Zutahy Y., and Lichter A., 2013. A method for evaluating fruit abscission potential of grapes and cherry tomato. Postharvest Biol. Technol., 79, 20-23.

Wittenbach V.A. and Bukovac M.J., 1974. Cherry fruit abscission: evidence for time of initiation and the involvement of ethylene. Plant Physiol., 54, 494-498. 